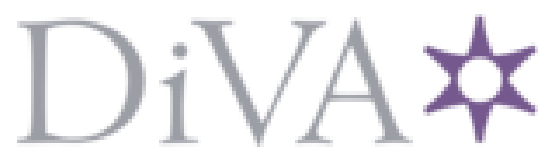

http://www.diva-portal.org

This is the published version of a paper published in Journal of Integrated Omnics.

Citation for the original published paper (version of record):

Hadrevi, J., Turkina, M V., Carlsson, A., Gerdle, B., Larsson, B. et al. (2016)

Myosin light chain and calcium regulating protein differences in chronic musculoskeletal neck and shoulder pain.

Journal of Integrated Omnics, 6(1): 191

http://dx.doi.org/10.5584/jiomics.v6i1.191

Access to the published version may require subscription.

N.B. When citing this work, cite the original published paper.

Permanent link to this version:

http://urn.kb.se/resolve?urn=urn:nbn:se:umu:diva-114519 


\author{
JOURNAL OF INTEGRATED OMICS \\ A METHODOLOGICAL JOURNAL \\ HTTP:/ /WWW.JIOMICS.COM
}

ORIGINAL ARTICLE | DOI: 10.5584/jiomics.v6i1.191

\title{
Myosin light chain and calcium regulating protein differences in chronic musculoskeletal neck and shoulder pain
}

\author{
Jenny Hadrévi ${ }^{1}$, Maria V. Turkina², Anders Carlsson³, Björn Gerdle³, Britt Larsson³, Fredrik Hellström4, Bijar Ghafouri
}

${ }^{1}$ Department of Community Medicine and Rehabilitation, Sports Medicine unit, Umeå University, SE 90187 Umeå, Sweden. ${ }^{2}$ Department of Clinical and Experimental Medicine, Linköping University, SE 58183 Linköping, Sweden ${ }^{3}$ Division of Community Medicine, Department of Medical and Health Sciences, Linköping University and Pain and Rehabilitation Center, Anesthetics, Operations and Specialty Surgery Center, Region Östergötland, SE 58185 Linköping, Sweden. ${ }^{4}$ Department of Occupational and Public Health Sciences, University of Gävle, 80176 Gävle, Sweden.

Received: 28 October 2015 Accepted: 27 December 2015 Available Online: 21 January 2015

\section{Abstract}

Proteomic screening analysis has detected myosin light chain (MLC) as a protein implied to be involved in chronic musculoskeletal neck and shoulder pain. Several analyses of MLC proteins have stated a difference in phosphorylation being the determining factor for protein activation hence altered contrability of the muscle in i.e. senescence. In continuation of a previous publication, this study is an attempt to analyze the different MLC isoforms by mass spectrometry and immune-analyses in myalgic and healthy trapezius muscle. In the present study no differences in phosphorylation level between the corresponding individual proteins were detected using LC-MSMS and immunoblotting; instead we assigned different isoforms of regulatory MLCs. To further elucidate the contrability: calcium $\left(\mathrm{Ca}^{2+}\right)$ regulatory proteins, sarco (endo)plasmic reticulum $\mathrm{Ca}^{2+}$ ATPase 1 (SERCA-1) and calsequestrine (CSQ) were analyzed by western blot. The analysis revealed a significantly increased abundance of SERCA-1 protein in the myalgic muscle and a significantly increased abundance of CSQ in healthy muscle. Myalgic muscle contraction patterns have in previous studies shown to differ from healthy muscle which may be connected to the Ca ${ }^{2+}$ availability in the muscle. Here we present the proteomic characterization of differences in $\mathrm{Ca}^{2+}$ regulating proteins and particularly regulatory MLCs in trapezius muscle of women with chronic musculoskeletal neck and shoulder pain.

Keywords: calcium $\left(\mathrm{Ca}^{2+}\right)$, mass spectrometry, phosphorylation, muscle pain, myosin light chain, trapezius.

\section{Abbreviations}

MLC: myosin light chain; MHC: myosin heavy chain; SERCA 1: sarco(endo)plasmic reticulum Ca ${ }^{2+}$ ATPase 1; CSQ: calsequestrin; two dimensional - differential gel analysis: 2D-DIGE; liquid chromatography mass spectrometry mass spectrometry: LCMSMS.

\section{Introduction}

The introduction of proteomics and metabolomics to the field of work related musculoskeletal disorders $[1,2]$ have suggested a difference in a number of proteins and metabolites relating to chronic musculoskeletal neck and shoulder pain (or chronic trapezius myalgia). These screening studies have presented proteins correlating to an altered metabolism, different contractibility and inflammatory and acute stress responses to differ in abundance between myalgic and healthy muscle [3].
Regulatory myosin light chain 2 (MLC2) was one protein appearing more abundant in chronic trapezius myalgia, according to a proteomic systematic explorative screening of the present biopsy material [2]. MLC2 has been a protein of interest in previous studies concerning sarcopenia (ageing muscle) [4-6] and muscle inactivity, such as during bed rest $[4,7,8]$. Phosphorylation of MLC2 has previously shown to affect the calcium sensitivity of skeletal muscle contraction [9], affecting the muscles ability to contract [10]. Fast regulatory MLC2 traditionally correlate with fast contracting type 2 fibers in skeletal muscle [11]. During low load work it

${ }^{\star}$ Corresponding author: Jenny Hadrévi, PhD. Department of Community Medicine and Rehabilitation, Sports Medicine Unit, Umeå University, Carl Skottsbergsgata Umeå University, 90187 Umeå, Sweden. E-mail address: jenny.hadrevi@umu.se 
has been shown that the muscle contraction in myalgic muscle is activated by a higher contribution of type 2 motor units compared to healthy muscle [12]. These several electromyographic studies indicate altered activation patterns of the trapezius muscle in subjects with chronic neck-shoulder pain conditions [13-15]. There is also discussed whether painful muscles are disused and clinically deconditioned [16]. One or both of these circumstances may be associated with altered contractility. A better understanding of molecular events related to contractility aspects can facilitate the development of targeted treatment interventions in subjects with chronic myalgia. Introducing proteins of $\mathrm{Ca}^{2+}$ regulation into this area of research may explain the excitation-coupling properties of the myalgic muscle. The result from the proteomic study suggesting the $\mathrm{Ca}^{2+}$ regulatory MLC2 fast to be more abundant in myalgic muscle [2], are one protein that may explain the differences in muscle contractility. The muscular symptoms associated with chronic trapezius myalgia are stiffness, tension and a decreased maximal force torque rate compared to healthy muscle $[17,18]$; and also the inability to relax the muscle during the naturally occurring pauses during dynamic work $[19,20]$.

In muscle contraction $\mathrm{Ca}^{2+}$ is regulating the contractility of the muscle and the regulatory myosin light chains, situated on the myosin head regulates the calcium sensitivity of the myosin molecule [21]. Sarco(endo)plasmic reticulum $\mathrm{Ca}^{2+}$ ATPase 1 (SERCA-1) transfers $\mathrm{Ca}^{2+}$ from the cytosol of the cell to the lumen of the sarcoplasmatic reticulum. SERCA-1 is predominately abundant in type 2 fibers [22]. Calsequestrine (CSQ) is the most abundant $\mathrm{Ca}^{2+}$ binding protein of the sarcoplasmatic reiculum in skeletal muscle [23]. CSQ releases $\mathrm{Ca}^{2+}$ upon muscle contraction and are available in two different isoforms, CSQ1 predominantly in type 2 muscle fibers and CSQ2 predominantly in type 1 [23]. CSQ buffer $\mathrm{Ca}^{2+}$ in the sarcoplasmatic reticulum thus assisting SERCA to not having to pump $\mathrm{Ca}^{2+}$ against a high concentration gradient [24]. Accumulation of $\mathrm{Ca}^{2+}$ in the muscle has been shown in rats exposed to prolonged chronic low frequency muscle stimulation and is hence proposed to be a mechanism behind chronic muscle pain $[25,26]$. The exact mechanisms behind this accumulation is yet not known, but serves as one of many hypothesis [27] behind the underlying pathophysiological mechanisms of chronic trapezius myalgia.

This study aims to characterize on proteomic level changes in $\mathrm{Ca}^{2+}$ regulating proteins in trapezius muscle of women with chronic trapezius myalgia and, in particular, to verify the possible difference in abundance of the phosphorylation of regulatory myosin light chain protein in healthy and myalgic trapezius muscle.

\section{Material and Methods}

The subjects, clinical examination, biopsy collection and
Two-Dimensional Difference Gel Electrophoresis (2-D DIGE) image analysis are presented in a previously published paper presenting a proteomic screening analysis of myalgic and healthy muscle [2]. In short the 2D-DIGE method was applied on frozen muscle samples that were suspended in lysis buffer and homogenized followed by protein quantification. Labelling of protein samples was made with CyDye minimal dyes, Cy2, Cy3 and $\mathrm{Cy} 5$, in accordance to manufacturers' protocol. The internal standard method was used [28]. The samples were applied onto $24 \mathrm{~cm}$ 3-11 Non-Linear (NL) Immobilised $\mathrm{pH}$ gradient (IPG) strips and rehydrated at room temperature in the dark for 16 hours. The first dimension was run using Amersham $\mathrm{Ettan}^{\mathrm{m}}$ IPGphor unit. Prior to the second dimension the gel strips was equilibrated and alkylated. The second dimension was conducted by using the Ettan DALT six apparatus. Gels were then immediately scanned with a Typhoon $^{\text {tw }} 9410$ scanner. The scanned image was further processed using ImageQuant $^{\text {mix }}$ V5.2 and DeCyder ${ }^{\text {ma }}$ V6.5. The 2D-DIGE protocol used has previously been evaluated [29]. A more detailed description of the analysis is available in Hadrevi et al 2013 [2].

Additional analysis and identification of the myosin light chain protein spots appearing on $2 \mathrm{D}$-gels that according to a number of publications previously presented $[4,6,7]$ are to be separated due to their individual level of phosphorylation. The main objective of our study is to identify the differences in phosphorylation between the different protein spots separated on a $2 \mathrm{D}$-gel that are of interest in the previous screening analysis [2], by utilizing phosphorylation analysis and high resolution mass spectroscopy, in accordance to the methods presented below:

\subsection{Phosphorylation analysis}

A preparative gel $(600 \mu \mathrm{g}$ protein) stained with Sypro Ruby was used for analysis by mass spectrometry. 10 protein spots corresponding to the different isoforms of myosin light chains were excised and in-gel digestion was performed according to previously described protocols [30]. The samples were analyzed by mass spectrometry. $200 \mu \mathrm{g}$ proteins were separated by 2D-PAGE. The ten protein spots corresponding to the different isoforms of myosin light chains were transferred from the gel by electroblotting to a PVDF membrane, blocked and incubated overnight with phosphor-threonine or phospho-tyrosine antibody (Cell Signaling Technology, Danvers, MA). Immunoreactive protein spots were detected using ECL prime detection system (GE Healthcare).

\subsection{High-Resolution Mass Spectrometry}

The obtained peptide mixtures were analyzed by LCMSMS. Separation was done using nano-flow HPLC system (EASY-nLC II, Thermo Fisher Scientific) and data were 
acquired using LTQ Orbitrap Velos Pro hybrid mass spectrometer (Thermo Fisher Scientific). Peptides were separated during $90 \mathrm{~min}$ by reverse phase chromatography on a $20 \mathrm{~mm} \times 100 \mu \mathrm{m}$ C18 pre column followed by a 100 $\mathrm{mm} \times 75 \mu \mathrm{m} \quad \mathrm{C} 18$ column (particle size $5 \mu \mathrm{m}$, NanoSeparations, Netherlands) at a flow rate $300 \mathrm{~nL} / \mathrm{min}$. A gradient of $0.1 \%$ formic acid in water (A) and $0.1 \%$ formic acid in acetonitrile (B) was distributed as follows: starting with $3 \% \mathrm{~B}$; linear gradient $3 \%-35 \% \mathrm{~B}$ in $0-60 \mathrm{~min}$; $35 \%-$ $90 \%$ B in $60-90 \mathrm{~min}$. Automated online analyses were performed with LTQ Orbitrap Velos Pro hybrid mass spectrometer (Thermo Fisher Scientific) with nano electrospray source; $240^{\circ} \mathrm{C}$ capillary temperature; spray voltage, $2200 \mathrm{~V}$. MS spectra were acquired in profile mode by FTMS at resolution of 30.000 (at $\mathrm{m} / \mathrm{z} 400$ ). Top 20 most intense multiply charged ions from were selected with an isolation window of 2.0 and fragmented in the linear iontrap by collision induced dissociation with normalized collision energy of 30. Dynamic exclusion of sequenced peptides for $60 \mathrm{~s}$ and charge state filtering disqualifying singly charged peptides were activated and predictive AGC was enabled. Centroid mode was used for CID MS/MS.

\subsection{Database Searches and Data Interpretation}

Obtained data files were analyzed by Proteome Discoverer 1.4 (Thermo Fisher Scientific) and the search algorithm SEQUEST was used against UniProt release 2013_09 Homo sapiens database. Carbamidomethylation of cysteine residues was set as static modification, and phosphorylation of threonine and serine and oxidation of methionine were set as variable modifications. Trypsin was used as the enzyme with 2 missed cleavages allowed. The precursor mass tolerance was set to $10 \mathrm{ppm}$ with $0.6 \mathrm{Da}$ fragment mass tolerance. Proteins were identified with at list 2 peptides of rank 1 with high score and target false discovery rate 0.01 .

\subsection{SERCA-1 and Calsequestrin analysis}

Muscle biopsies were heat stabilized using Stabilizor T1 device (Denator AB, Sweden). The biopsies were homogenized in lysis buffer (Protein Simple, Santa Clara, $\mathrm{CA}$ ) and by sonication $3 \times 10 \mathrm{~s}$. The samples were stored for $2 \mathrm{~h}$ at $4^{\circ} \mathrm{C}$ and then centrifuged for $1 \mathrm{~h}$ at $4 \times 10^{4} \mathrm{~g}$ at $5^{\circ} \mathrm{C}$. The supernatant was then removed to a new tube. Total protein concentrations were measured by 2-D Quant kit (GE Healthcare) according to the manufactures recommendation. Samples were diluted to adjust protein concentration to $1 \mu \mathrm{g} / \mu \mathrm{l}$ in $5 \mu \mathrm{l}$ with sample buffer. The quantification of expression level of SERCA-1 was performed by a novel nanovolume capillary electrophoresis based protein analysis, Simple western size/charge assay instrument Peggy ${ }^{\mathrm{m}}$ [31]. The lysate samples were mixed with a master mix containing $80 \mathrm{mM}$ DTT, fluorescent molecular markers and heated at $95^{\circ} \mathrm{C}$ for 10 minutes. The samples, blocking reagents, primary antibody, secondary antibody and chemiluminescence substrate were loaded onto a 384well plate according to the user manual provided by the company (Protein Simple, Santa Clara, CA). The primary antibody (SERCA-1; Abcam, Calsequestrin;Novus Biological) was diluted in antibody diluent in a 1:50 dilution. The chemiluminescence signals were digitized using a charge coupled camera (CCD). The digital images were analyzed with Compass software (ProteinSimple), and the quantified data of the detected protein were reported as molecular weight and peak area.

\subsection{Statistical analysis}

The proteomic data was analyzed using a multivariate projection model, projections to latent structures with discriminant analysis (PLS-DA) [32]. PLS-DA is a supervised linear regression method used to find a relationship between $\mathrm{X}$ variables (spot volume ratios) and a binary $\mathrm{Y}$ vector by using class membership data (MYA/ $\mathrm{CON})$. The spot volume ratios were mean centered and scaled for unified variance. The number of PLS-DA components was determined by full cross-validation (SIMCA-P version 12, Umetrics $\mathrm{AB}$, Umeå, Sweden). The PLS-DA model was also validated by both response permutation tests and CV-ANOVA on the residuals [33]. To identify spot of interest variable of importance value (VIP) $>1$ was used.

For the traditional statistical analyses IBM SPSS (version 22) was used. Mann-Whitney U test was used for the group comparisons of SERCA-1 and CSQ. A p-value $<0.05$ was considered statistically significant.

\section{Results}

\subsection{Myosin light chains}

Proteins of interest in this analysis are MLC proteins and adjacent protein spots in the $2 \mathrm{D}$ gel analysis presented in figure 1A. Previous studies have presented the 2D-gel protein pattern of human skeletal muscle [34] and the possible correlation between a regulatory MLC and myalgia [2]. PLS-DA of the 2D- protein pattern from 12 female cleaners with work-related trapezius myalgia and 12 pain free female cleaners reveals the importance of the ten investigated proteins in separating between MYA and CON. Proteins with VIP $>1$ were, two fast regulatory MLC, H3BN54 and H3BML9) (VIP 1.41 and 1.04 respectively) and one slow MLC Q6IB42 (VIP 1.09) (figure 1B). The other proteins showed $\mathrm{VIP}<1$. The ten protein spots (figure $1 \mathrm{~A}$ ) were analyzed by mass spectrometry. The results showed that the ten spots were different proteins with different molecular weight and pI. The sequences of each individual protein isoform, obtained from the LC-MS analysis are here presented as supplement information. Phosphorylated peptides were detected at one position in spot 4-5 (table 1). There were no phosphorylated peptides in spot 6-10. The 


\section{A}
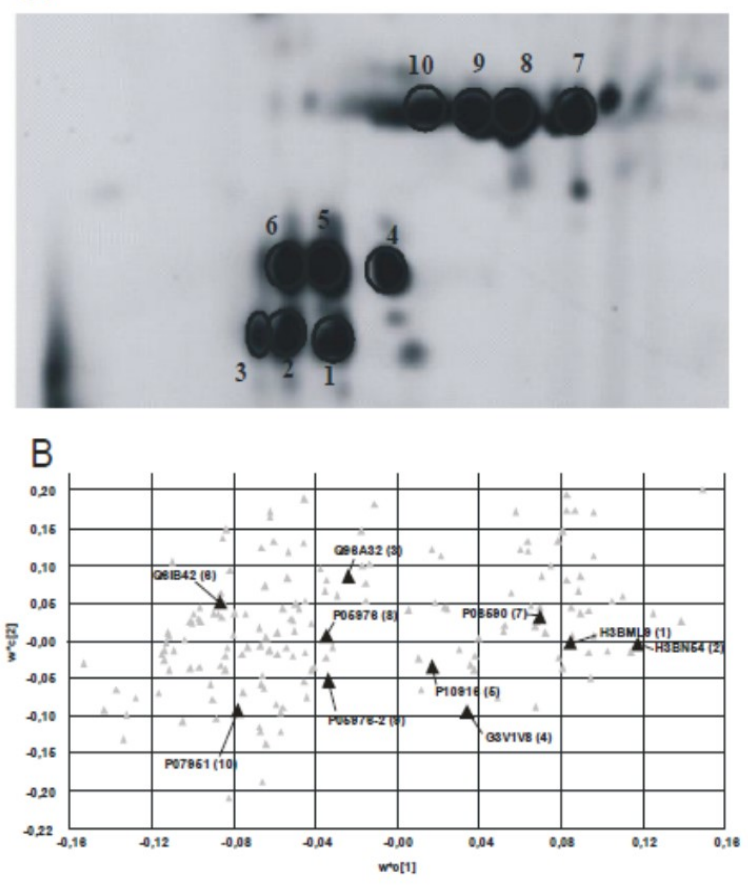

Figure 1. A) The typical 2D-gel image of muscle protein extract enlarged at 4.9-5.4 $\mathrm{pH}$ (theoretical) range. The marked spots are referred to the spot numbers in table 1. B) PLS-DA weight plot $\left(\mathrm{w}^{*} \mathrm{c}[1] / \mathrm{w}^{*} \mathrm{c}[2]\right)$ with proteins involved in the separation of MYA (right) and CON (left). PLS-DA model: $\left(\mathrm{Q}^{2}(\mathrm{cum})=0.65,\left(\mathrm{R}^{2}\right.\right.$ (cum) $=0.29$, component $1: 16 \%$, component $2: 13 \%$ explained variance). Identified myosin light chain proteins included in the analysis are marked with larger black triangles. Smaller gray triangles are other proteins within the PLS-DA model (2).

immunological investigation of phosphorylation of the ten proteins could not detect any tyrosine phosphorylation on the proteins. No significant difference in threonine phosphorylation was detected on spots corresponding to the different MLCs.

\subsection{Proteins of calcium regulation}

The immunological automated western blot detection of SERCA-1 and CSQ- 1 showed that the level of SERCA-1 was significantly higher $(\mathrm{p}=0.017$, figure $2 \mathrm{~A}$ ) in myalgic muscle compared to healthy, indicative of an increased activity in calcium channel activity connected to calcium release ad uptake actions in the SR of the muscle regulating the contractile actions of the muscle. The level of CSQ was decreased $(\mathrm{p}=0.010$, figure $2 \mathrm{~B})$ in myalgic muscle compared to healthy muscle, suggesting a decreased calcium buffering capacity in the myalgic muscle. These significant results support the results from the myosin light chain analysis suggesting an altered calcium regulation in the myalgic muscle.

\section{Discussion}

The performed LC-MSMS analysis allowed us for the first time to pinpoint and characterize 9 myosin light chain isoforms (table 1) previously named as differentially phosphorylated isoforms of MLC. Surprisingly, no difference in phosphorylation between spots was detected according to present MS-analyses, additionally confirmed both by serine and tyrosine phosphorylation immunodetection on 2D gels. Phosphorylation of myosin light chain proteins has in previous studies been attributed to contractile function of the myosin molecule [11], additional results are presented showing phosphorylated and dephosphorylated muscles develop the same isometric tension at full $\mathrm{Ca}^{2+}$ saturation [35]. In rats an increased phosphorylation due to increased neuronal activity is observed when the muscle transitions from slow to fast muscle [36, 37]. Altered phosphorylation of MLC may also be indicative of disease [38]. Transformation of fast isoforms of MLC to slow isoforms has shown to occur together with MHC transformation, according to proteomic profiling of senescent muscle [4-6]. This has also been evidential in senescent muscle rat models [4] where increases of MLC slow has been shown. Together the MHCs and the MLCs dictate the contractile function of the myosin molecule. Laboratory experiments on rat conclude that hybrid fibers, fibers expressing different isoforms of MHC and MLC, appear in muscle transition when a muscle remodel from slow to fast. Recent studies indicate an increased remodeling of the myalgic muscle due to an increased amount of satellite cells and metabolites connected to muscle remodeling [39, 40].

To further elucidate the potential difference in muscle $\mathrm{Ca}^{2+}$ regulation the abundance of a calcium regulatory protein analysis of the $\mathrm{Ca}^{2+}$ channel protein SERCA-1 [22] and CSQ, a protein of $\mathrm{Ca}^{2+}$ storing [41] were performed. The influence of $\mathrm{Ca}^{2+}$ levels and the pathophysiological mechanisms of trapezius myalgia have been discussed by Gissel et al 2005 [25] presenting the $\mathrm{Ca}^{2+}$ accumulation theory [26]. Gissel et al. have in laboratory animal models shown that low force static work induces $\mathrm{Ca}^{2+}$ accumulation in the muscle subjected to long term stimulation, causing a leakage of lactate dehydrogenase that will induce a pain potentiation. Lactate is a substrate of anaerobic metabolism which has been a marker of muscle damage [42] but recent studies have shown that it is an energy substrate of anaerobic metabolism being transported out of the cell by the lactate shuttle acting as fuel elsewhere [42-46]. The synthesization of glycogen is also increased in anaerobic conditions $[47,48]$ and increased glycogen has been shown to have an impact on $\mathrm{Ca}^{2+}$ release in the skeletal muscle $[49,50]$. In coherence, enzymes active in the glycogen transformation, metabolizing glycogen in the glycolysis, has been shown to occur with a higher abundance in myalgic muscle compared to healthy [2]. 
Table 1. Myosin light chain (MLC) protein isoforms identified from trapezius muscle by 2D gel and following mass spectrometry analyses. The spot numbers are referred to the marked spots in figure 2. Sequenced phosphorylated peptides are shown. VIP $=$ variable of importance in projection from the PLS-DA analysis (figure 1B).

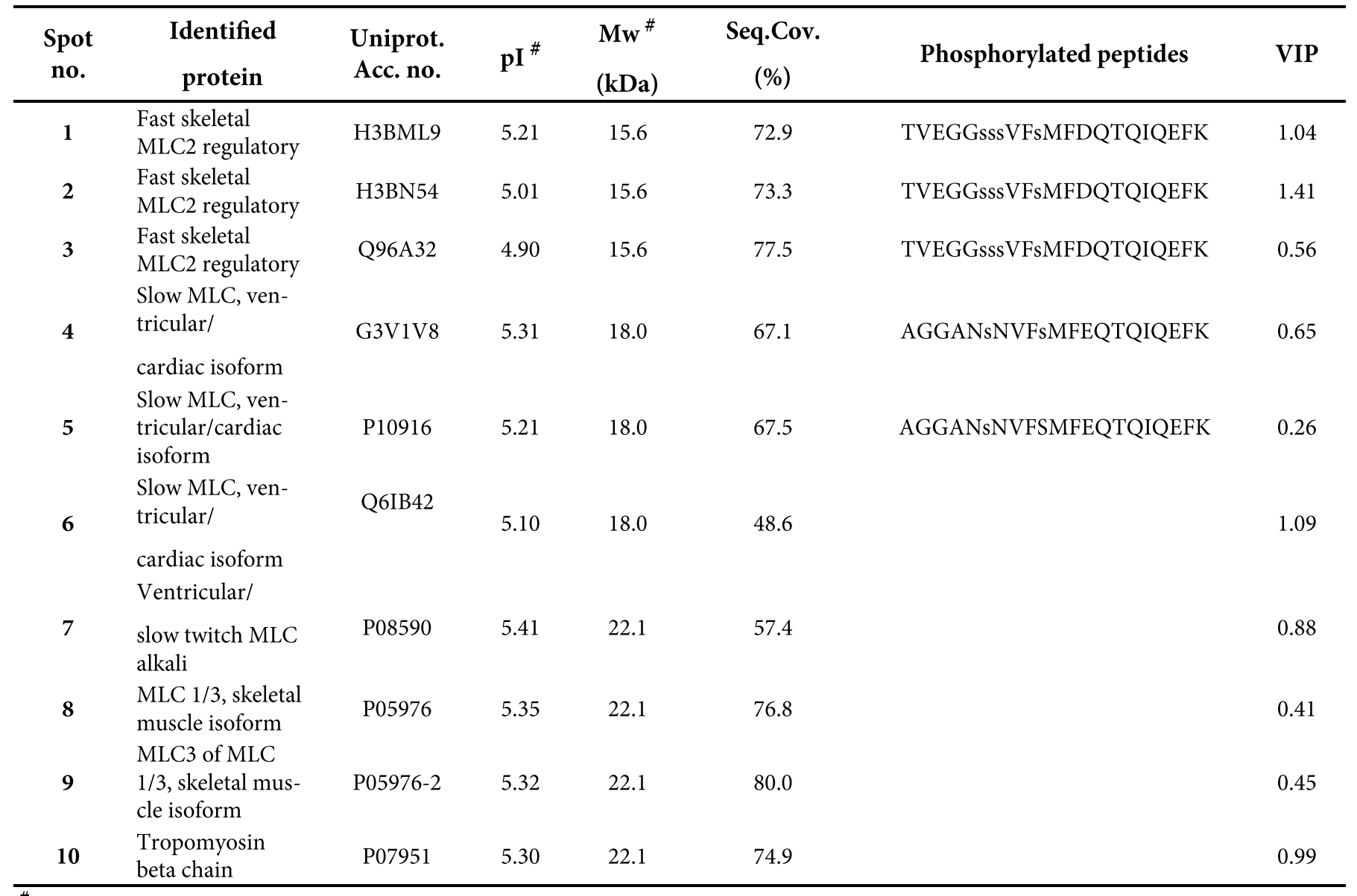

\# Calculated.

In the present study, myalgic muscle exhibits a significantly increased abundance of SERCA-1 compared to healthy muscle (figure 2A). The SERCA-1 protein has shown to exist in both types of fibers but in a considerably higher abundance in type 2 fibers [51]. The increased abundance of SERCA-1 in myalgic muscle indicates a difference in the contractile characteristics of myalgic muscle compared to healthy muscle. Previous studies have shown an impaired ability to relax the myalgic muscle during the pauses that are occurring in a standardized dynamic work [20]. Since the SERCA-1 proteins are determinants of the $\mathrm{Ca}^{2+}$ influx and efflux of the muscle sarcolemma, where the efflux is crucial for the muscle relaxation rate. In this material where there is no difference in fiber type content [52], though the high amount of SERCA-1 is indicative of fast twitch characteristics of myalgic muscle as it resequesters $\mathrm{Ca}^{2+}$ enabling a fast relaxation of the muscle. When CSQ subsequentially binds $\mathrm{Ca}^{2+}$ it will buffer and keep the $\mathrm{Ca}^{2+}$ comparatively low and still have a large amount of $\mathrm{Ca}^{2+}$ ready to be released to produce muscle contraction [23, 41]. SERCA also enables leakage out of the SR and since the $\mathrm{Ca}^{2+}$ uptake by SERCA is energy consuming where a higher concentration of ADP will reduce $\mathrm{Ca}^{2+}$ uptake in the SR [24].
Fast twitch fiber normally generates force in a rapid manner, in comparison to slow twitch type 1 fibers. Fast twitch fibers hence needs to have a substantial amount of $\mathrm{Ca}^{2+}$ stored in the SR to be released rapidly upon stimulation [53] in order to saturate the calcium binding sites on troponin C. Recent laboratory investigations have shown a reduced rate of torque development in patients suffering from trapezius myalgia $[17,18]$. CSQ is a protein that buffers $\mathrm{Ca}^{2+}$ in order to upon strong stimuli release $\mathrm{Ca}^{2+}$ to enable muscle contraction. Type 2 fibers have been shown to be more dependent on CSQ availability compared to type 1, due to their specific contractile properties [54]. CSQ knockout mice show a reduced ability to quickly generate maximal force during muscle contraction [54-56], similar the muscular traits of chronic muscle myalgia $[17,18,20]$. Also, CSQ could be connected to an increased fatigability of the myalgic muscle. The lower abundance of CSQ in myalgic muscle compared to healthy muscle may explain the muscular traits of the myalgic muscle although this specific correlation has not yet been presented.

Also, a proposed pain inducing calcium accumulation could be obtained by a lack of buffering capacity in the SR and energy deficits disturbing ATP consuming SERCA 
A)

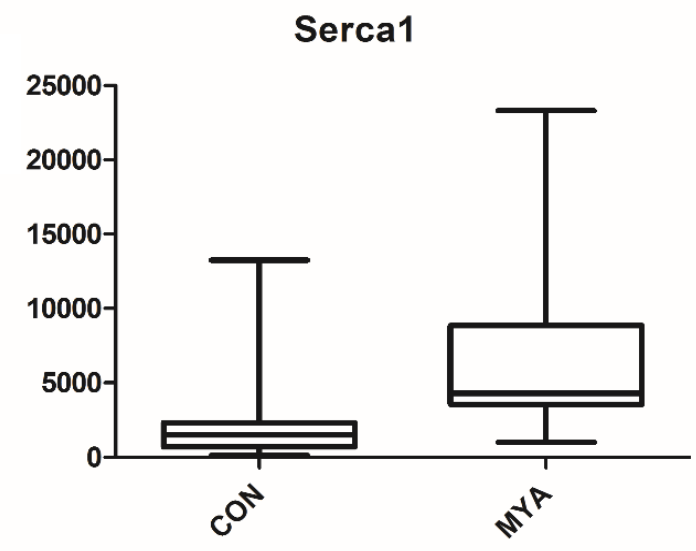

B)

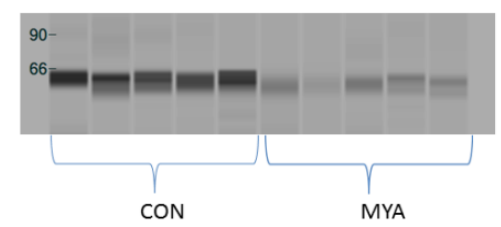

Calsequestrin

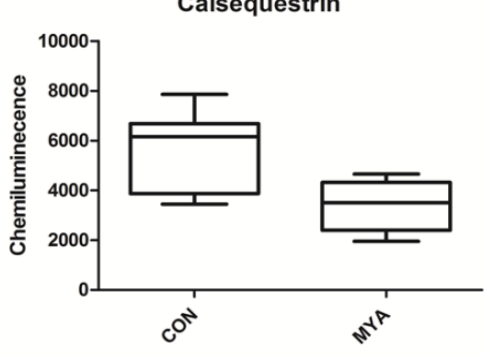

Figure 2: A) SERCA-1 significantly more abundant in myalgic muscle (MYA $n=11)$ compared to healthy $(C O N, n=11) p=0.017$. B) CSQ is significantly less abundant in myalgic muscle (MYA) compared to healthy $(\mathrm{CON}) \mathrm{p}=0.010$, bars describe variation, and boxes median values. The abundance of CSQ illustrated by gel from western blot analysis of myalgic patients (MYA) and healthy $(\mathrm{CON})$.

activity. Though, a more comprehensive analysis needs to be performed with specific antibodies analysis of the different CSQ isoforms and protein abundance in individual muscle fibers. In addition the rate at which SERCA moves $\mathrm{Ca}^{2+}$ across the SR membrane can be controlled by the regulatory proteins phospholamban (PLB) [57] and sarcolipin [58], reducing the rate of $\mathrm{Ca}^{2+}$ movement. Future studies are needed to elucidate the relationship between the different $\mathrm{Ca}^{2+}$ regulatory proteins and their inhibitors in myalgic muscle to understand the mechanisms of muscle pain.

In conclusion, our results show an increased abundance of fast regulatory MLC, a higher abundance of SERCA-1 proteins and a lower abundance of CSQ in myalgic muscle compared to healthy. On the basis of previous knowledge, the phosphorylations of the proteins are analyzed showing no difference in phosphorylation between individual MHC protein $2 \mathrm{D}$-gel spots. Instead the MLC proteins are characterized presenting different isoforms of the MLC. The presented results indicate differences between healthy subjects and subjects with chronic trapezius myalgia with respect to contractile molecular events. The results have to be confirmed in other studies and also elucidating if the cause e.g. pain per se, different activation pattern or deconditioning/disuse. Such knowledge will be of importance for designing targeted treatment interventions for patients with chronic myalgia. Muscle stiffness and weakness, increased muscle tension and a reduced capacity to rapidly generate force are some of the muscular symptoms of chronic work related muscle pain. Increasing the understanding regarding the biochemical mechanisms of muscle myalgia will render increased knowledge concerning the concrete muscular symptoms of myalgia.

\section{Concluding Remarks}

The present work contributes to the understanding of the complexity of mechanisms of muscular adaptation and especially with relevance for contractile properties due to work related muscle pain. In this study we suggest that the physiological mechanisms behind the previously shown differences in force output and endurance in muscle contraction in myalgic patients may have a relation to the pathological alterations of proteins connected to the calcium regulation of the muscle. When investigating other proteins of calcium regulation there is an evident significant difference in their abundance comparing healthy and myalgic muscle. The increased abundance of the calcium ion channel protein SERCA-1 suggests an increased cellular exchange of calcium in the myalgic muscle. In addition there is a lower abundance of the calcium buffering protein CSQ in myalgic muscle which considering previous evidence are a protein prone to cause the intrinsic contractile properties of chronic work related myalgia. Further investigations regarding calcium content in the muscle needs to be done before any conclusion regarding the calcium activity and its relation to the contractile properties of myalgic muscle can be made.

\section{Supplementary material}

Supplement information: Protein sequences and phosphorylated sites of detected proteins presented in table 1.

\section{Acknowledgements}

This study was supported by the Swedish Council for Working Life and Social Research (2010-0683, 2007-0760, 2012-0726, 2013-1259); the Swedish Research Council (2010 -2893 \& K2015-99x-21874-05-4). The funders had no role in study design, data collection and analysis, decision to publish, or preparation of the manuscript. 


\section{References}

1] P. Olausson, B. Gerdle, N. Ghafouri, B. Larsson, B. Ghafouri, PLoS One, 7 (2012) e52560. doi: 10.1371/ journal.pone.0052560

2] J. Hadrevi, B. Ghafouri, B. Larsson, B. Gerdle, F. Hellström, PLoS One, 8 (2013) e73285. doi: 10.1371/ journal.pone.0073285

3] J. Hadrévi, Journal of Musculoskeletal Pain, Dec 2014 Vol. 22 (2014) 382-388. doi: doi:10.3109/10582452.2014.949335

4] J. Gannon, P. Doran, A. Kirwan, K. Ohlendieck, Eur J Cell Biol., 88 (2009) 685-700. doi: 610.1016/j.ejcb.2009.1006.1004. Epub 2009 Jul 1019. doi: 10.1016/j.ejcb.2009.06.004

5] K. Ohlendieck, Front Physiol, 2 (2011) 105. doi: 10.3389/ fphys.2011.00105

6] C. Gelfi, A. Vigano, M. Ripamonti, A. Pontoglio, S. Begum, M.A. Pellegrino, B. Grassi, R. Bottinelli, R. Wait, P. Cerretelli, J Proteome Res, 5 (2006) 1344-1353. doi: 10.1021/pr050414x

7] M. Moriggi, M. Vasso, C. Fania, D. Capitanio, G. Bonifacio, M. Salanova, D. Blottner, J. Rittweger, D. Felsenberg, P. Cerretelli, C. Gelfi, Proteomics, 10 (2010) 3756-3774. doi: 10.1002/pmic.200900817

8] L. Stevens, B. Bastide, J. Hedou, C. Cieniewski-Bernard, V. Montel, L. Cochon, E. Dupont, Y. Mounier, Arch Biochem Biophys., 540 (2013) 125-132. doi: 110.1016/ j.abb.2013.1010.1016. Epub 2013 Oct 1031. doi: 10.1016/ j.abb.2013.10.016

9] D. Szczesna, Curr Drug Targets Cardiovasc Haematol Disord., 3 (2003) 187-197.

10] W. Melzer, A. Herrmann-Frank, H.C. Luttgau, Biochim Biophys Acta., 1241 (1995) 59-116.

11] H.L. Sweeney, B.F. Bowman, J.T. Stull, Am J Physiol. , 264 (1993) 1085-1095

12] L.A. Kallenberg, H.J. Hermens, Eur J Appl Physiol., 96 (2006) 203-208. Epub 2004 Sep 2029. doi: 10.1007/s00421-004-12151

13] K.B. Veiersted, R.H. Westgaard, P. Andersen, Int Arch Occup Environ Health., 62 (1990) 31-41.

14] P. Madeleine, B. Lundager, M. Voigt, L. Arendt-Nielsen, Int Arch Occup Environ Health., 76 (2003) 39-49. Epub 2002 Oct 2001.

15] J.E. Elert, S.B. Rantapaa-Dahlqvist, K. Henriksson-Larsen, R. Lorentzon, B.U. Gerdle, Scand J Rheumatol., 21 (1992) 28-34.

16] J.A. Verbunt, R.J. Smeets, H.M. Wittink, Pain., 149 (2010) 428 430. doi: 410.1016/j.pain.2010.1001.1020. Epub 2010 Feb 1012. doi: 10.1016/j.pain.2010.01.020

17] L.L. Andersen, A. Holtermann, M.B. Jorgensen, G. Sjogaard, Clin Biomech (Bristol, Avon). 23 (2008) 1237-1242. doi: 1210.1016/j.clinbiomech.2008.1208.1002. Epub 2008 Oct 1232. doi: 10.1016/j.clinbiomech.2008.08.002

18] L.L. Andersen, P.K. Nielsen, K. Sogaard, C.H. Andersen, J. Skotte, G. Sjogaard, J Biomech., 41 (2008) 2029-2035. doi: 2010.1016/j.jbiomech.2008.2003.2016. Epub 2008 May 2025. doi: 10.1016/j.jbiomech.2008.03.016

19] L.L. Andersen, C.H. Andersen, J.H. Skotte, C. Suetta, K. Sogaard, B. Saltin, G. Sjogaard, Biomed Res Int., 2014:187324. (2014) 10.1155/2014/187324. Epub 182014 Feb 187323. doi: $10.1155 / 2014 / 187324$

20] B. Larsson, J. Bjork, J. Elert, B. Gerdle, Eur J Appl Physiol., 83 (2000) 257-267.

21] D. Pette, R.S. Staron, Rev Physiol Biochem Pharmacol., 116 (1990) 1-76

22] M. Periasamy, A. Kalyanasundaram, Muscle Nerve., 35 (2007) 430-442.
23] R.M. Murphy, N.T. Larkins, J.P. Mollica, N.A. Beard, G.D. Lamb, J Physiol., 587 (2009) 443-460. doi: 410.1113/ jphysiol.2008.163162. Epub 162008 Nov 163124. doi: 10.1113/jphysiol.2008.163162

24] C.R. Lamboley, R.M. Murphy, M.J. McKenna, G.D. Lamb, J Physiol., 592 (2014) 1381-1395. doi: 1310.1113/ jphysiol.2013.269373. Epub 262014 Jan 269327. doi: 10.1113/ jphysiol.2013.269373

25] H. Gissel, Ann N Y Acad Sci., 1066 (2005) 166-180. doi: 10.1196/annals.1363.013

26] H. Gissel, T. Clausen, Acta Physiol Scand., 171 (2001) 327-334. doi: 10.1046/j.1365-201x.2001.00835.x

27] B. Visser, J.H. van Dieen, J Electromyogr Kinesiol, 16 (2006) 116. doi: $10.1016 /$ j.jelekin.2005.06.005

28] A. Alban, S.O. David, L. Bjorkesten, C. Andersson, E. Sloge, S. Lewis, I. Currie, Proteomics, 3 (2003) 36-44. doi: 10.1002/ pmic.200390006 [doi]

29] C. Malm, J. Hadrevi, S.A. Bergström, F. Pedrosa-Domellöf, H. Antti, M. Svensson, L. Frängsmyr, Scand J Clin Lab Invest, 68 (2008) 793-800. doi: 10.1080/00365510802277464

30] B. Ghafouri, K. Irander, J. Lindbom, C. Tagesson, M. Lindahl, J Proteome Res., 5 (2006) 330-338. doi: 10.1021/pr050341h

31] J.Q. Chen, M.R. Heldman, M.A. Herrmann, N. Kedei, W. Woo, P.M. Blumberg, P.K. Goldsmith, Anal Biochem., 442 (2013) 97-103. doi: 110.1016/j.ab.2013.1007.1022. Epub 2013 Jul 1026.

32] S. Wold, M. Sjöström, L. Eriksson, Chemometrics and Intelligent Laboratory Systems, 58 (2001) 109-130

33] L. Eriksson, J. Trygg, S. Wold, J Chemometrics, 22 (2008) 594600

34] C. Gelfi, S. De Palma, P. Cerretelli, S. Begum, R. Wait, Electrophoresis, 24 (2003) 286-295. doi: 10.1002/ elps.200390025

35] K. Midde, R. Rich, P. Marandos, R. Fudala, A. Li, I. Gryczynski, J. Borejdo, J Biol Chem., 288 (2013) 7012-7023. doi: 7010.1074/jbc.M7112.434209. Epub 432013 Jan 434214. doi: 10.1074/jbc.M112.434209

36] C. Bozzo, B. Spolaore, L. Toniolo, L. Stevens, B. Bastide, C. Cieniewski-Bernard, A. Fontana, Y. Mounier, C. Reggiani, Febs J., 272 (2005) 5771-5785. doi: 10.1111/j.17424658.2005.04965.x

37] B. Gonzalez, P. Negredo, R. Hernando, R. Manso, Pflugers Arch., 443 (2002) 377-386. Epub 2001 Sep 2026. doi: 10.1007/ s004240100702

38] C. Sutherland, M.P. Walsh, J Biol Chem., 287 (2012) 2406424076. doi: 24010.21074/jbc.M24112.371609. Epub 372012 May 371631. doi: 10.1074/jbc.M112.371609

39] A.L. Mackey, L.L. Andersen, U. Frandsen, C. Suetta, G. Sjogaard, J Appl Physiol, 109 (2010) 1920-1929. doi: 10.1152/ japplphysiol.00789.2010

40] J. Hadrevi, B. Ghafouri, A. Sjors, H. Antti, B. Larsson, A.G. Crenshaw, B. Gerdle, F. Hellstrom, Eur J Appl Physiol, 28 (2013) 28. doi: 10.1007/s00421-013-2716-6

41] C.R. Lamboley, R.M. Murphy, M.J. McKenna, G.D. Lamb, J Physiol., 591 (2013) 6053-6068. doi: 6010.1113/ jphysiol.2013.265900. Epub 262013 Oct 265914. doi: 10.1113/ jphysiol.2013.265900

42] P. Brancaccio, G. Lippi, N. Maffulli, Clin Chem Lab Med, 48 (2010) 757-767. doi: 10.1515/CCLM.2010.179

43] G.A. Brooks, J Physiol, 587 (2009) 5591-5600. doi: 10.1113/ jphysiol.2009.178350

44] N. Draoui, O. Feron, Dis Model Mech, 4 (2012) 727-732. doi: 10.1242/dmm.007724

45] L.B. Gladden, J Physiol, 558 (2004) 5-30. doi: 10.1113/ jphysiol.2003.058701 
46] A. Philp, A.L. Macdonald, P.W. Watt, J Exp Biol, 208 (2005) 4561-4575. doi: 10.1242/jeb.01961

47] N. Pescador, D. Villar, D. Cifuentes, M. Garcia-Rocha, A. Ortiz -Barahona, S. Vazquez, A. Ordonez, Y. Cuevas, D. SaezMorales, M.L. Garcia-Bermejo, M.O. Landazuri, J. Guinovart, L. del Peso, PLoS One., 5 (2010) e9644. doi: 9610.1371/ journal.pone.0009644.

48] J. Pelletier, G. Bellot, P. Gounon, S. Lacas-Gervais, J. Pouyssegur, N.M. Mazure, Front Oncol., 2:18. (2012) 10.3389/fonc.2012.00018. eCollection 02012.

49] N. Ortenblad, J. Nielsen, B. Saltin, H.C. Holmberg, J Physiol., 589 (2011) 711-725. doi: 710.1113/jphysiol.2010.195982. Epub 192010 Dec 195986. doi: 10.1113/jphysiol.2010.195982

50] D.G. Stephenson, J Physiol., 589 (2011) 451. doi: 410.1113/ jphysiol.2010.203943. doi: 10.1113/jphysiol.2010.203943

51] V.A. Fajardo, E. Bombardier, C. Vigna, T. Devji, D. Bloemberg, D. Gamu, A.O. Gramolini, J. Quadrilatero, A.R. Tupling, PLoS One., 8 (2013) e84304. doi: 84310.81371/ journal.pone.0084304. eCollection 0082013. doi: 10.1371/ journal.pone.0084304

52] B. Larsson, J. Bjork, J. Elert, R. Lindman, B. Gerdle, Eur J Appl Physiol, 84 (2001) 492-502

53] M. Beltran, G. Barrientos, C. Hidalgo, Biol Res., 39 (2006) 493503. Epub 2006 Nov 2007. doi: /S0716-97602006000300011

54] C. Paolini, M. Quarta, L. D'Onofrio, C. Reggiani, F. Protasi, J Biomed Biotechnol., 2011:634075. (2011) 10.1155/2011/634075. Epub 632011 Sep 634014. doi: $10.1155 / 2011 / 634075$

55] C. Paolini, M. Quarta, A. Nori, S. Boncompagni, M. Canato, P. Volpe, P.D. Allen, C. Reggiani, F. Protasi, J Physiol., 583 (2007) 767-784. Epub 2007 Jul 2012. doi: 10.1113/ jphysiol.2007.138024

56] F. Protasi, C. Paolini, M. Canato, C. Reggiani, M. Quarta, J Muscle Res Cell Motil., 32 (2011) 257-270. doi: 210.1007/ s10974-10011-19277-10972. Epub 12011 Dec 10971.

57] B.L. Akin, T.D. Hurley, Z. Chen, L.R. Jones, J Biol Chem., 288 (2013) 30181-30191. doi: 30110.31074/jbc.M30113.501585. Epub 502013 Aug 501531. doi: 10.1074/jbc.M113.501585

58] S.K. Sahoo, S.A. Shaikh, D.H. Sopariwala, N.C. Bal, M. Periasamy, J Biol Chem., 288 (2013) 6881-6889. doi: 6810.1074/jbc.M6112.436915. Epub 432013 Jan 436922. 